\title{
MULTILETRAMENTOS: COMPREENSÃO E IDENTIDADES ATRELADAS ÀS MÍDIAS SOCIAIS ESTADUNIDENSES
}

\section{ARTIGO ORIGINAL}

BATISTA, Carlos ${ }^{1}$

BATISTA, Carlos. Multiletramentos: compreensão e identidades atreladas às mídias sociais estadunidenses. Revista Científica Multidisciplinar Núcleo do Conhecimento. Ano 06, Ed. 09, Vol. 03, pp. 137-156. Setembro de 2021. ISSN: 2448-0959, Link de acesso: https:/www.nucleodoconhecimento.com.br/educacao/compreensao-e-identidades, DOI: 10.32749/nucleodoconhecimento.com.br/educacao/compreensao-e-identidades

\section{RESUMO}

O presente artigo visa esmiuçar os entendimentos a respeito de determinados conceitos relacionados ao processo de ensino-aprendizagem, os quais são intrínsecos à nossa sociedade contemporânea, sendo eles: a alfabetização, o letramento $\mathrm{e}$, consequentemente, o multiletramento, este último tratado como o objetivo central do estudo. Todos estão atrelados a questão norteadora do texto que visa explicitar estas concepções, entrelaçar suas aplicações e usos com as redes sociais norte-americanas. Com base nesta metodologia de pesquisa bibliográfica, o artigo, descreve ao longo do seu desenvolvimento 4 (quatro) destas redes: o Orkut, - Facebook, o Instagram e o YouTube. Tratados como objetivos específicos da pesquisa, estes foram escolhidos devido à sua importância histórica e abrangência social. Realizadas as conexões, explicitados os conceitos e desenvolvida a questão norteadora, o artigo, conclui que o fenômeno das redes sociais digitais incita à

\footnotetext{
${ }^{1}$ Pós-graduado em Metodologia do Ensino da Língua Inglesa (Faculdade São Luís); Pós-graduado em Redação e Oratória (Faculdade São Luís); Pós-graduado em Literatura Brasileira (Faculdade São Luís); Pós-graduado em MBA em Marketing e Vendas (FMU); Pós-graduado em Docência do Ensino Superior (FMU); Pós-graduado em Formação em Educação a Distância (UNIP); Bacharelado em Desenho Industrial (FAAP); Graduado em LetrasInglês (UNIP); Graduando em Tecnologia da Informação (UNIP).
}

RC: 97006

Disponível em: https://www.nucleodoconhecimento.com.br/educacao/compreensaoe-identidades 
prática social de costumes e ideologias em vista dos aspectos tecnológicos que vivenciamos em nosso dia a dia, isto é, o processo de letramento digital ou comumente denominado de multiletramento se tornou a base, a infraestrutura para criação, disseminação, popularização destas redes sociais e, consequentemente, dos meios digitais que as permeiam.

Palavras-chaves: alfabetização, letramento, multiletramento, redes digitais, educação.

\section{INTRODUÇÃO}

A principal questão norteadora deste artigo é entender brevemente a compreensão do fenômeno do multiletramento na contemporaneidade, sua história pregressa e a relação intrínseca que ela pode desenvolver com as mídias sociais estadunidenses, a tornando, muitas vezes, um produto midiático destes meios.

O letramento digital envolto aos meios sociais pode ser tipificado como o objetivo geral deste estudo, uma vez que será detalhado de uma forma mais ampla ao longo do desenvolvimento.

Portanto, para alicerçar está problemática e propor soluções ao final do estudo, abordaremos, primeiramente, alguns conceitos importantes como a alfabetização, o letramento e o multiletramento, em tópicos diferenciados, demonstrados de forma sequencial, com o intuito de apresentar uma compreensão linear de todo o contexto pesquisado (BARBOSA, 2016).

Abordar cada conceito, mesmo que de forma sucinta, é primordial para o desenvolvimento de uma produção acadêmica (BARBOSA, 2016), por consequência, os objetivos específicos passam a ser contemplados.

Os objetivos específicos deste artigo reforçam à assimilação da base teórica atrelada às mídias digitais. Para isto, foram escolhidas quatro redes sociais norteamericanas: o Orkut, como a pioneira (GNIPPER, 2020), o Facebook, como a

RC: 97006

Disponível em: https://www.nucleodoconhecimento.com.br/educacao/compreensaoe-identidades 
principal rede de entretenimento utilizada atualmente (GNIPPER, 2020), o Instagram, como uma rede voltada ao uso de imagens (GNIPPER, 2020), e, por fim, - YouTube, devido ao fenômeno de sucesso atrelado aos vídeos divulgados pelos seus membros (GNIPPER, 2020).

Sendo assim, a metodologia utilizada será a pesquisa conceitual e bibliográfica, ilustrando brevemente a história de cada rede social descriminada, revelando suas aplicabilidades, técnicas e abordagens sociais, enveredadas ao cenário do multiletramento.

No entanto, não intencionamos descrever detalhadamente a história pregressa de cada uma das redes digitais mencionadas, mas sim, esclarecer o contexto em que estão inseridas, permitindo, assim, reflexões acadêmicas e sociais voltadas ao ambiente em que se desenvolvem.

A delimitação de 4 (quatro) redes sociais digitais norte-americanas, em meio a um universo digital vasto, se deve a importância histórica destas no fenômeno da cibercultura (LÉVY, 2009) e sua abrangência socioeconômica atual.

\section{DA ALFABETIZAÇÃO AO MULTILETRAMENTO}

Ao longo do desenvolvimento deste tópico procuramos responder o que vem a ser alfabetização. De acordo com Soares (2004), se associarmos a ela um conceito subsequente, como o letramento, a temática se torna completa e pode ser mais bem explorada, explicitada e respondida.

\subsection{ALFABETIZAÇÃO COMO O INÍCIO DE TODO O PROCESSO}

Para entender melhor o termo alfabetização, ressaltaremos duas definições. A primeira, exemplificada por Drumond (SISTEMAMAXI, 2020): "[...] alfabetização se refere especificamente à aprendizagem e domínio do código alfabético."

E a segunda, descrita por Soares (2004), define a alfabetização como:

RC: 97006

Disponível em: https://www.nucleodoconhecimento.com.br/educacao/compreensaoe-identidades 
Em síntese, [...] a [...] alfabetização, entendida como processo de aquisição e apropriação do sistema da escrita, alfabético e ortográfico; em segundo lugar, e como decorrência, a importância de que a alfabetização se desenvolva num contexto de letramento - entendido este, no que se refere à etapa inicial da aprendizagem da escrita, como a participação em eventos variados de leitura e de escrita, e o conseqüente desenvolvimento de habilidades de uso da leitura e da escrita nas práticas sociais que envolvem a língua escrita, e de atitudes positivas em relação a essas práticas (SOARES, 2004).

Isto significa, na prática, que o processo de alfabetizar está atrelado intimamente ao processo de aprender, isto é, conhecer, interiorizar e se apropriar do alfabeto[2] e da língua vernácula da região em que o indivíduo pretende se comunicar (ROJO; MOURA, 2019).

O que parece simples de teorizar de fato não é, pois, é preciso o domínio indispensável de regras entre as letras (vocábulos), representados pelos grafemas[3] e os seus sons, representados pelos fonemas[4].

Alfabetizar uma pessoa se tornou mais complexo com o tempo, antes, no início do século XX, um indivíduo alfabetizado era uma pessoa que sabia ler poucas palavras e assinar o seu próprio nome, àqueles que não detinham está aptidão eram considerados analfabetos. A alfabetização, também, evocava "status" de ser domínio de pessoas das elites (religiosas e políticas) e das que viviam em centros urbanos (ROJO; MOURA, 2019).

A partir da década de 70 cunhou-se o termo (an)alfabetismo funcional, o qual significa, em termos práticos, segundo Castro (BRASIL ESCOLA, 2020): "São chamados de analfabetos funcionais os indivíduos que, embora saibam reconhecer letras e números, são incapazes de compreender textos simples, bem como realizar operações matemáticas mais elaboradas".

Analfabetos funcionais são pessoas que não tem o traquejo, ou melhor, o domínio de situações diversas do dia a dia, (ROJO; MOURA, 2019), que exigem um nível de complexidade maior, como utilizar um cartão magnético em um banco ou calcular as prestações de um empréstimo e, até mesmo, saber interpretar textos mais complexos, como relatórios, livros e contratos.

RC: 97006

Disponível em: https://www.nucleodoconhecimento.com.br/educacao/compreensaoe-identidades 
A questão norteadora deste artigo, está centrada nesta perspectiva, e é sobre ela que discorremos nos próximos tópicos.

Imagem 01: Alfabetização

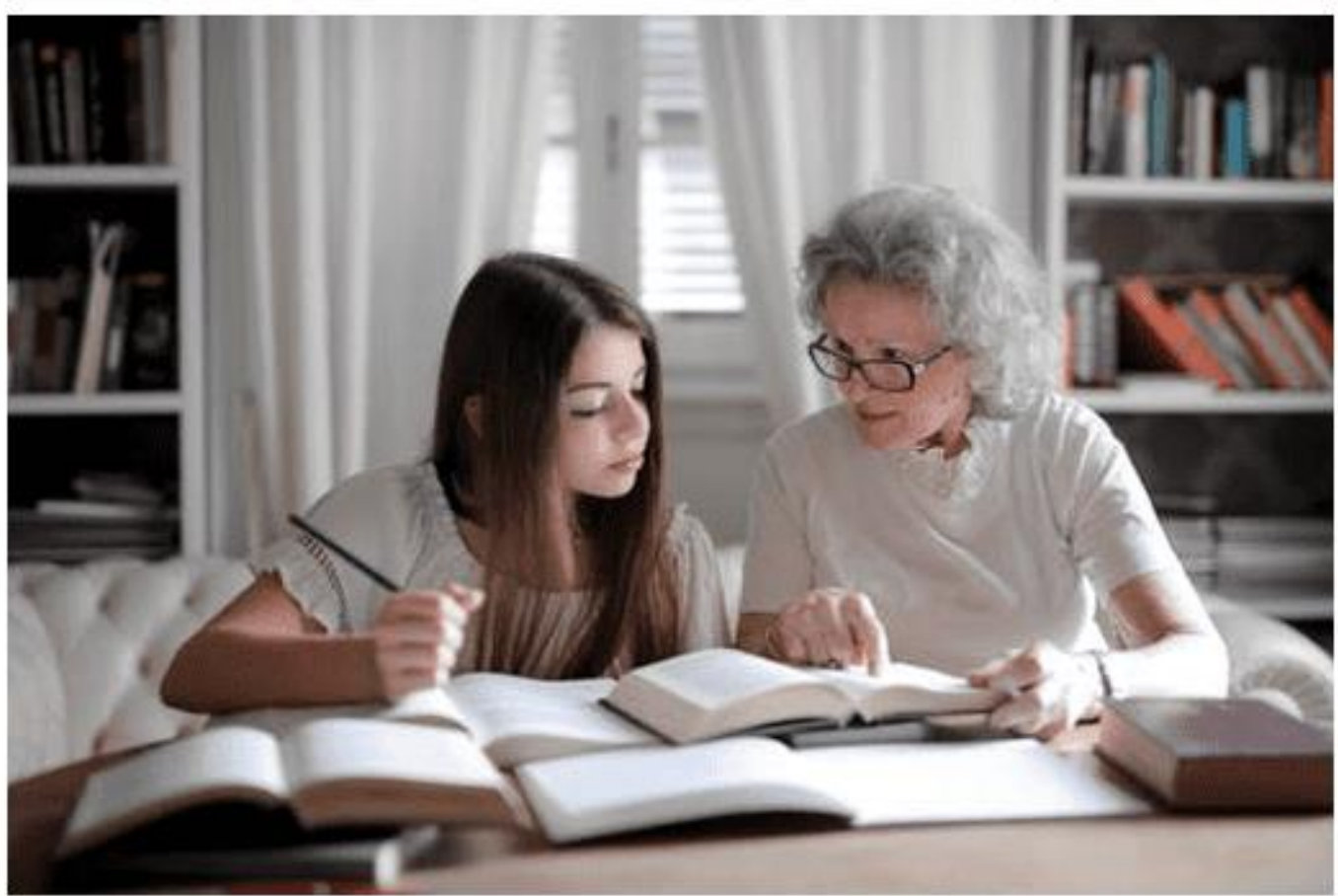

Fonte: Pexels, 2021.

\subsection{LETRAMENTO COMO EVOLUÇÃO NECESSÁRIA À ALFABETIZAÇÃO}

Iniciamos o desenvolvimento deste tópico, abordando uma reflexão proeminente: não basta ser alfabetizado, é preciso, também, ser "letrado" na língua.

O que isto quer dizer? Quer dizer que é aconselhável aprender (em número cada vez maior) o conjunto de códigos, símbolos e suas aplicações em nossa sociedade (ROJO; MOURA, 2019).

RC: 97006

Disponível em: https://www.nucleodoconhecimento.com.br/educacao/compreensaoe-identidades 
A história do termo letramento e sua aplicação também é enumerada pela pesquisadora Magda Soares em seu artigo: "Letramento e alfabetização: as muitas facetas" (2004):

[...] em meados dos anos de 1980 que se dá, simultaneamente, a invenção do letramento no Brasil, do illettrisme, na França, da literacia, em Portugal, para nomear fenômenos distintos daquela denominada alfabetização, alphabétisation. Nos Estados Unidos e na Inglaterra, embora a palavra literacy já estivesse dicionarizada desde o final do século XIX, foi também nos anos de 1980 que o fenômeno que ela nomeia, distinto daquele que em língua inglesa se conhece como reading instruction [...] (SOARES, 2004).

Para Soares (2009, p. 39 apud GRANDO, 2012, p. 6) letramento significa:

Resultado da ação de ensinar e aprender as práticas sociais de leitura e escrita; O estado ou condição que adquire um grupo social ou um indivíduo como consequência de ter-se apropriado da escrita e de suas práticas sociais. (SOARES, 2009, p. 39, apud GRANDO, 2012, p. 6).

A indagação de poder praticar e aprender, tanto a leitura como a escrita, são a nova realidade do contexto social. O termo (e vocábulo) "letramento" traduz, em suma, uma nova percepção, em que a sociedade inicia um processo de depuração, aperfeiçoamento da prática de ler e escrever, não mais em sua forma mecânica, usual ou considerada estritamente necessária.

Com isso, praticar "atividades letradas", envolve também o: letramento escolar, o letramento artístico e o letramento profissional[5], de forma presente e essencial. (GUIMARÃES, 2020)

A questão do letramento pode ser entendida como longas e históricas práticas de "atividades letradas" em nossa sociedade (ROJO; MOURA, 2019).

No início, os primeiros alfabetos, rudimentares ou não, surgiram com a necessidade de registrar através da escrita os feitos dos deuses, dos reinos e seus costumes. Posteriormente, o letramento, migrou da religião para a cultura, como na Idade 
Média, onde a igreja guardava os seus registros sagrados apenas aos letrados e versados em seus propósitos.

Posteriormente, a invenção e aprimoramento da prensa por Gutenberg, permitiu a popularização de literaturas impressas, onde a réplica e distribuição se tornou cada vez mais democrática e acessível, assentando novos letramentos.

A Revolução Industrial trouxe meios, máquinas e ferramental para as sociedades contemporâneas alcançarem novas formas na distribuição da escrita, permitindo novos formatos e consequentemente novos públicos (BARBOSA, 2016).

Porém, o grande salto se deu com os novos meios de comunicação, tanto das formas radiofônicas, como, posteriormente, televisivas, cinematográficas e, por fim, digitais.

Todo este processo permitiu atingirmos patamares atuais de necessidades e compreensão das escritas tradicionais e dos letramentos.

Portanto, o objetivo geral do artigo, se faz presente com a enumeração das múltiplas linguagens, as quais nos levaram a um novo padrão de compreensão: o multiletramento.

\subsection{MULTILETRAMENTO: COMPREENSÃO E IDENTIDADES}

Já referido como o objetivo geral para o entendimento desta pesquisa, o termo multiletramento, não deve ser visto simplesmente como uma evolução do letramento em si (ROJO; MOURA, 2019), mas sim, a evolução das necessidades peculiares de nossa cultura, percebida e cunhada principalmente a partir do final do século $X X$, onde os novos conteúdos midiáticos[6] passaram a surgir e ganhar força.

A concepção de multiletramento, foi iniciada, através de um grupo de pesquisadores de diferentes nacionalidades, reunidos nos Estados Unidos, na cidade de New

RC: 97006

Disponível em: https://www.nucleodoconhecimento.com.br/educacao/compreensaoe-identidades 
England (Nova Londres), estado de New Hampshire, onde formaram, o que ficou conhecido, como GNL (New London Group). (ROJO; MOURA, 2019)

Imagem 02: The New London Group

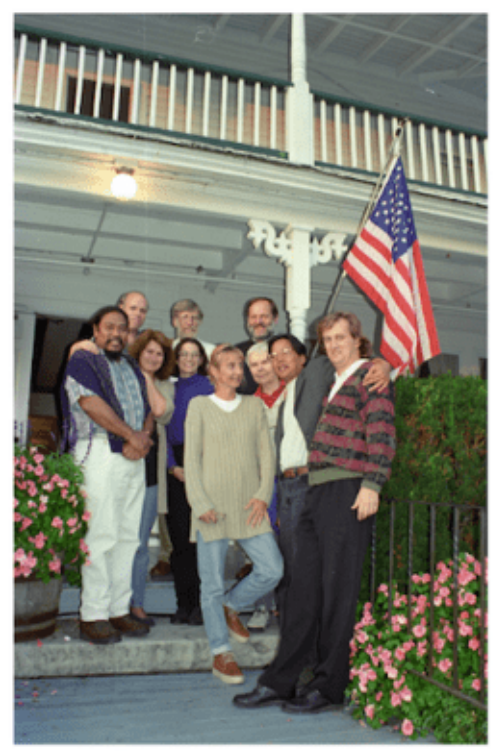

The New London Group

Marin Nakata

James Paul Gee

Mary Kalantzis

Sarah Michaels

Carmen Luke

Norman Fairclough

Courtney Cazden

Gunther Kress

Allan Luke

Bill Cope

New London, New Hampsbire, September 1994

Cope \& Kalantzis • Transpositional Grammar • meaningpatterns.net/new-london-group

Fonte: Works \& Days, 2020.

Os pesquisadores do The New London Group[7] (GNL) ressaltavam o impacto inevitável da composição das novas mídias digitais na formação dos textos (SOUZA; CARDOSO, 2011).

Para Rojo e Moura (2019, p. 19), o GNL: "[...] ressaltavam que os textos, em parte devido ao impacto das mídias digitais, estavam mudando e já não mais eram essencialmente escritos, mas se compunham de uma pluralidade de linguagens, que eles denominaram: multimodalidade".

Está "aceleração" de impactos estava atrelada à globalização, uma vez que, existia uma profusão cada vez maior de mídias e diversidades sociais, culturais e étnicas. Rojo e Moura (2019, p. 21) complementam: "Isso tinha impacto não somente nos textos, que se tornavam cada vez mais multimodais, mas também na diversidade 
cultural e linguística das populações, o que implicaria mudanças necessárias na educação para o que chamaram de multiletramentos".

Portanto, o termo multiletramento, está atrelado a duas frentes igualmente complementares:

- Em uma primeira opção: toda diversidade cultural que a permeia com a inserção cada vez maior de culturas, costumes e formatos multiculturais;

- Em uma segunda opção: o letramento em si está associado a múltiplas culturas e, principalmente, às múltiplas linguagens disponíveis em um número cada vez maior. (BARBOSA, 2016)

Sendo assim, o multiletramento, não deve ser mensurado simplesmente como uma evolução do letramento, mas sim a "raiz", isto é, o radical do termo multi[8], onde multiletramentos, devem significar de fato, os diversos tipos de letramentos atrelados as mais diversas produções de discursos e textos (BARBOSA, 2016). Reunindo, assim, uma característica essencial que o torna único: a multimodalidade.

As novas tecnologias digitais trouxeram avanço ao multiletramento digital, dentre estes destacamos o TDIC (Tecnologias Digitais de Informação e Comunicação). Sobre elas, Costa; Duqueviz e Pedroza (2015, p. 608) enumeram:

As TDIC têm exercido a função de instrumentos mediadores dos processos de aprendizagem dos nativos digitais quanto a aprender a conhecer e aprender a fazer em vivências cotidianas ou no acesso à cultura tecnopopular. As novas tecnologias parecem influenciar e impactar a constituição de sujeitos dos usuários em grande potencial das tecnologias digitais $[\ldots]$.

Rojo; Moura (2019) apontam, também, algumas características complementares, dentre elas: a aprendizagem estimulando novas práticas sociais e 0 fato dos multiletramentos se tornarem multimodais e, principalmente, multifacetados.

O resultado é observado através dos inúmeros recursos que o multiletramento propicia, dentre eles, estão os hiperlinks. 
O linguista Marcuschi (2010) salienta que houve uma mudança na maneira que atualmente lemos e, as modificações que surgiram durante todo esse processo de criação dos hipertextos, além das demais características dos gêneros digitais.

O fenômeno do hyperlink possibilitou criar o que denominamos como hipertexto. De acordo com Arantes (apud SILVA, 2017) um hipertexto bem-produzido e compreendido, deve respeitar 3 (três) características importantes:

- Flexibilidade na escrita, interatividade e marcas constantes de discursos orais;

- Coesão, coerência e intertextualidade evidentes;

- Noção de produção escrita em coerência com os aspectos locais e globais do texto, além da presença de hyperlinks que funcionam como os verdadeiros operadores de coesão do texto (SILVA, 2017).

Os hipertextos ganham "vida", por assim dizer, com os hyperlinks[9], e embasando todo este novo modelo de letramento, há a literatura, tanto brasileira como a estrangeira.

Este meio, só tem continuidade, forma, amparo e desenvolvimento devido as bases nas mídias sociais, em especial, nas redes sociais de origem norte-americanas.

\section{MÍDIAS SOCIAIS ESTADUNIDENSES}

O fenômeno das mídias sociais norte-americanas, no mundo atual globalizado, se deve ao sucesso de suas redes sociais digitais e o seu alcance (GNIPPER, 2020).

Hoje, estamos permeados por tecnologias e mídias que facilitam cada vez mais a comunicação, encurtando distâncias, e estabelecendo formas de comunicação "instantânea", transformando a maneira com que as pessoas se comunicam. (LÉVY, 2009)

Neste ponto, há uma convergência entre mídias, tecnologias, informações e comunicações configurando, assim, as redes sociais digitais. De acordo com 
Recuero (2009, p. 24 apud SANTOS; SANTOS, 2014, p. 310), o conceito de rede pode ser entendido como:

[...] uma rede,[...], é uma metáfora para observar os padrões de conexão de um grupo social, a partir das conexões estabelecidas entre os diversos atores. A abordagem de rede tem, assim, seu foco na estrutura social [...]. O estudo das redes sociais na internet,[...], foca o problema de como as estruturas sociais surgem, de que tipo são, como são compostas através da comunicação mediada pelo computador e como essas interações mediadas são capazes de gerar fluxos de informação e trocas sociais que impactam suas estruturas.

Ou seja, as redes sociais são palpáveis: "[...] não apenas em pessoas e grupos sociais, mas também em artefatos, dispositivos e entidades" (SANTAELLA; LEMOS, 2010, p. 40 apud SANTOS; SANTOS, 2014, p. 310).

As redes sociais são o meio e as possibilidades (SANTOS; SANTOS, 2014), foram criadas para o ciberespaço e são imersas nele (LÉVY, 2009), são alimentadas pelos seus usuários, através dos dispositivos que usam (tablets, smartphones e computadores, por exemplo).

Uma de suas principais vantagens são os conteúdos midiáticos, onde o compartilhamento das informações se torna praticamente "obrigatório" (SANTOS; SANTOS, 2014), sendo alimentado pelos seus usuários de forma constante. Assim, tanto os consumidores como os produtores, se tornam um só e o letramento digital[10] se torna onipresente.

Esta evolução comunicacional se faz presente desde os primórdios de nosso processo de alfabetização (SANTOS; SANTOS, 2014). O advento das redes sociais digitais vem alicerçar a isto, apoiando a técnica e a tecnologia na evolução de formatos anteriormente utilizados, que foram ou estão sendo descontinuados em vista da realidade que vivemos e da forma que consumimos os conteúdos multimodais. 
Imagem 03: Mídias Sociais Digitais

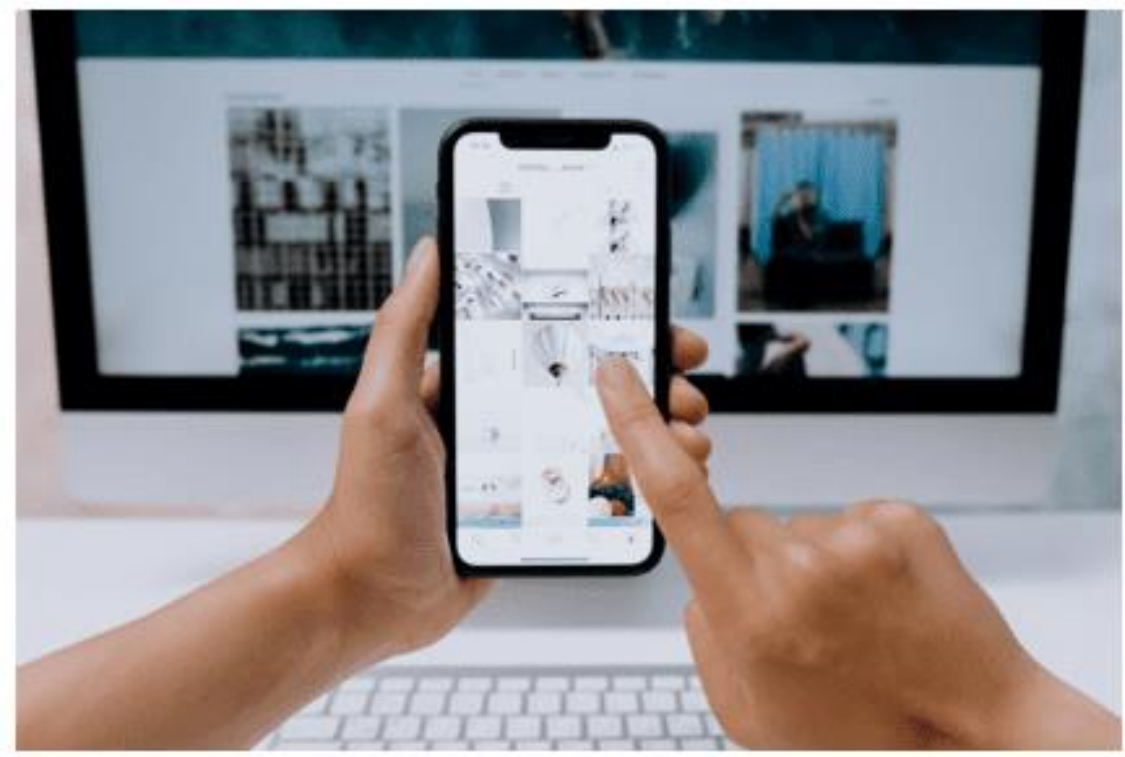

Fonte: Pexels, 2021.

\subsection{CONCEITOS E DISCURSOS MIDIÁTICOS}

Descrever historicamente as redes sociais digitais norte-americanas se torna sempre um desafio, não só pela quantidade destas e sua importância (GNIPPER, 2020), mas também, principalmente, por seu universo permeado pelos conceitos de multiletramento, multimodalidade e por todo o aspecto semiótico[11] que envolve o conteúdo.

A seguir, abordaremos em quatro subitens as redes sociais: Orkut, Facebook, Instagram e YouTube (GNIPPER, 2020) com o propósito de facilitar à compreensão de todo o contexto.

\subsection{A REDE SOCIAL ORKUT}

Criada em 2004, pelo turco Orkut Büyükkökten, se tornou referência como à primeira rede digital, social e mundial de grande popularidade. 
Orkut Büyükkökten, que foi funcionário do Google, é engenheiro por formação com PhD em ciência da computação pela Universidade de Stanford (KLEINA, 2018). Em 2001, criava suas primeiras iniciativas na área como o Clube Nexus, até ingressar na empresa (Google) que abraçou sua ideia e permitiu lançar o Orkut.

A rede social Orkut, foi a pioneira em estabelecer uma forma de comunicação entre os seus usuários, promovendo gostos e informações, além de ser difusora de conhecimentos, hábitos e relacionamentos entre os seus integrantes (SANTOS; SANTOS, 2014).

A questão do multiletramento já era utilizada desde o início, pois os usuários precisavam se cadastrar determinando seus dados principais e características. Após este cadastro, eles poderiam ingressar nas comunidades criadas, compartilhando, assim, os mesmos interesses, realçando conceitos midiáticos, como exemplifica Torres (2009, p. 137 apud SANTOS; SANTOS, 2014, p. 311):

O conceito do Orkut é bastante simples: você cria um perfil, composto por uma série de informações pessoais, fotos e vídeos, e pode convidar membros para serem seus amigos. Esses amigos passam a poder ver as atualizações de seu perfil e a trocar mensagens com você. Além disso, você pode criar uma comunidade, com fórum de discussão, eventos e enquetes, ligada a qualquer tema que imaginar, e convidar pessoas a participarem dela.

Esta rede se tornou popular em diversas partes do mundo, especialmente no Brasil onde alcançou mais de 700 mil usuários em seu primeiro ano de divulgação. (KLEINA, 2018)

Após sucessivos desgastes entre os seus usuários, comunidades e o lançamento de novas redes sociais digitais, rivalizando assim em concorrência e conteúdo, a rede foi oficialmente desativada pelo Google em 2014 (KLEINA, 2018).

O mérito principal da rede Orkut foi ser a "porta de entrada" para um letramento virtual que se esforçava a todo instante em ser um "não virtual". O Orkut, também, marcou o início do uso de uma série de ferramentas sociais e digitais norte- 
americanas que visavam estreitar os laços de comunicação entre os seus usuários utilizando plataformas e meios digitais.

\subsection{O FACEBOOK, A MAIOR REDE SOCIAL DO MUNDO}

O Facebook, criado em Fevereiro de 2004, pelo até então estudante da Universidade de Harvard, Mark Zuckeberg, teve seu início focando inicialmente nos graduandos da própria universidade em que Zuckeberg estudava, sendo aberto, ao público em geral, somente 2 (dois) anos depois (SANTOS; SANTOS, 2014).

O sucesso do Facebook, se deve basicamente às ferramentas interacionais e aos mecanismos de segurança propostos, diferentemente do Orkut, que foi desativado justamente por não conter tais ferramentas e mecanismos. Torres (2009, p. 172 apud SANTOS; SANTOS, 2014, p. 312, adaptado) ressalta em seu artigo que o Facebook: "[...] é mais privado [a sua utilização] que outros sites de redes sociais [digitais], pois apenas usuários que fazem parte da mesma rede [comunidade] podem ver o perfil uns dos outros". Portanto, esta rede traz mais segurança, visando um maior controle do perfil dos usuários e a possibilidade de realização de auditorias[12] constantes.

O Facebook, aprimorou de forma eficaz as ferramentas de engajamento entre os seus usuários, incentivando, de forma persistente, o uso de imagens e, se profissionalizou, com a adoção de propagandas pagas e perfis corporativos.

Com isto, o multiletramento, se faz ainda mais presente e garantiu uma audiência crescente, desde o seu lançamento, ao ponto de ter ultrapassado o Orkut em número de usuários cadastrados em 2011 (KLEINA, 2018), e, ser pioneiro em muitos recursos como o engajamento em mídias digitais através da opção de curtir fotos (botão like), lançado em 2009 (KLEINA, 2018) e a Timeline, recurso que transforma a página pessoal do usuário em um mural fotográfico, com fotos de seu cotidiano e eventos em sua vida.

RC: 97006

Disponível em: https://www.nucleodoconhecimento.com.br/educacao/compreensaoe-identidades 


\subsection{O INSTAGRAM, UMA REDE VOLTADA AO USO DE IMAGENS}

O Instagram, cujo início das operações se deu em 2010, é uma rede essencialmente visual, isto é, com conteúdos que mesclam fotos e vídeos entre os seus usuários. Sua criação se deve ao brasileiro Mike Krieger e o americano Kevin Systrom (AGUIAR, 2018).

Atualmente, o dono desta rede é o próprio Facebook, que a comprou em 2012 (AGUIAR, 2018). Assim como no Facebook, fazem parte da experiência do usuário os conceitos de "curtir", exibir fotos e vídeos no seu perfil e a utilização do Instagram Stories[13].

O Instagram, se torna uma rede mais simples de ser manuseada, uma vez que as principais interações são realizadas através de imagens dispostas, facilitando assim, o seu letramento. Santos e Santos (2014, p. 313) detalham:

Suas funções são simples e rápidas. Basta um clique e a escolha de um filtro para que as fotos e/ou vídeos se tornem visualizadas pelos usuários do Instagram e de demais redes sociais (Facebook, Twitter, Tumblr, Foursquare e Flickr). Assim como as outras redes sociais digitais mencionadas é "gratuito", porém, para ser utilizado é necessário o uso de um smartphone ou tablet com o aplicativo instalado disponibilizado para sistema Android ou iOS.

\subsection{O YOUTUBE E A DEMOCRATIZAÇÃO DE ACESSO AOS VÍDEOS}

A cerca de 15 anos atrás, era impensável utilizar e publicar vídeos na web sem operar ferramentas pagas ou outros tipos de comunicadores, como os e-mails (KLEINA, 2018).

O YouTube, surgiu para mudar isto, iniciado em Fevereiro de 2005 pelos exfuncionários da PayPal, Chad Hurley, Jawed Karim e Steve Chen, a proposta inicial de democratizar o acesso, a publicação (e posteriormente também edição) de vídeos pessoais e profissionais. (KLEINA, 2018)

RC: 97006

Disponível em: https://www.nucleodoconhecimento.com.br/educacao/compreensaoe-identidades 
Está rede social digital ressalta um "espírito" empregado no contexto atual das redes sociais mundiais, iniciado, alardeado e consolidado especialmente pelas redes estadunidenses, Burgess e Green (2009, p. 20-21, adaptado), enumeram este fato:

Nesses primeiros momentos o site [YouTube] trazia o slogan Your Digital Video Repository ("Seu Repositório de Vídeos Digitais"), uma declaração que, de alguma maneira, vai de encontro à exortação atual, e já consagrada, Broadcast yourself (algo como "Transmitir-se"). Essa mudança de conceito do site - de um recurso de armazenagem pessoal de conteúdos em vídeo para uma plataforma destinada à expressão pessoal - coloca o YouTube no contexto das noções de uma revolução liderada por usuários que caracteriza a retórica em torno da "Web 2.0"

Os conceitos midiáticos, multiculturais e democráticos[14] que permeiam está rede, explicam o seu sucesso, especialmente entre a faixa etária mais jovem, uma vez que a mesma já se habituou a concepções intrínsecas inerentes ao letramento digital e multiletramento (SANTOS; SANTOS, 2014).

Finalizamos as descrições com o breve relato do YouTube, pois é propósito do trabalho enumerar algumas redes sociais digitais fundamentadas na metodologia acadêmica determinada e nos objetivos específicos estabelecidos.

Ressaltar suas características comuns (GNIPPER, 2018), advindas de um país da América do Norte (Estados Unidos) que incentiva a produção de conteúdos digitais, se torna fundamental, pelo fato desta nação ser justamente à base[15] deles.

\section{CONSIDERAÇÕES FINAIS}

A questão principal que norteia está produção acadêmica envolvia os entendimentos sobre o multiletramento e sua relação intrínseca com as redes sociais norteamericanas.

Entendemos que, ao final destas abordagens, a relação não só existe, como é permeada pela conjuntura social e econômica a qual vivenciamos.

RC: 97006

Disponível em: https://www.nucleodoconhecimento.com.br/educacao/compreensaoe-identidades 
As mídias sociais digitais funcionam, como o produto, ou melhor, o resultado deste processo de imersão e aprendizado digital.

Todo o processo se iniciou, como enumera o artigo, com a alfabetização, posteriormente, com o letramento e, por fim, culmina com o próprio multiletramento.

O artigo também busca conectar e tornar partes diferentes em partes de um todo, ou seja, entrelaçar teorias de pesquisadores na área e estabelecer uma cronologia de abordagens de forma sequencial.

Contudo, podemos concluir, em especial, que o analfabetismo funcional se tornou um conceito cada vez mais presente e que as consequências atuais deste fenômeno são uma sociedade ainda desprovida de letramentos digitais, tanto acadêmica como profissionalmente. (SOUZA; CARDOSO, 2011)

A popularização das redes sociais em meio a ambientes digitais pode trazer à resposta do porquê este meio se tornou presente e, muitas vezes, necessário para o desenvolvimento etário das populações (especialmente de baixa faixa etária) e na popularização de negócios.

Tendo estes pressupostos, nos últimos itens foram apresentadas algumas redes sociais norte-americanas, vinculadas aos objetos de estudos neste trabalho (Orkut, Facebook, Instagram e YouTube).

Sua resumida história e aplicações servem para elucidar o papel cada vez maior destes meios digitais sociais e suas consequências na maneira que nos comunicamos, moldando inclusive nossa sociedade (LÉVY, 2009).

Salientamos a necessidade inerente do ser humano, não somente de se comunicar, mas, principalmente, de utilizar as redes sociais como forma de expressar as suas ideologias, sendo as redes sociais digitais, um campo fértil para esta movimentação e aplicação do multiletramento, como um campo teórico que serve como base para todo este entendimento.

RC: 97006

Disponível em: https://www.nucleodoconhecimento.com.br/educacao/compreensaoe-identidades 


\section{REFERÊNCIAS}

AGUIAR, Adriana. Instagram: saiba tudo sobre esta rede social! Blog. Rockcontent. 17 ago, 18. Disponível em: https://rockcontent.com/br/blog/instagram/. Acesso em: 14 set. 2020.

BARBOSA, Jacqueline P. Sobre novos e multiletramentos, culturas digitais e tecnologias na escola. Plataforma do LETRAMENTO. 2016. Disponível em: http://www.plataformadoletramento.org.br/em-revista-coluna-detalhe/1044/sobrenovos-e-multiletramentos-culturas-digitais-e-tecnologias-na-escola.html. Acesso em: 12 set. 2020.

BURGESS, Jean; GREEN, Joshua. YouTube e a Revolução Digital : como o maior fenômeno da cultura participativa transformou a mídia e a sociedade; tradução Ricardo Giassetti. - São Paulo : Aleph, 2009. Disponível em: https://edisciplinas.usp.br/pluginfile.php/2205278/mod_resource/content/1/Burgess\% 20et\%20al.\%20-\%202009\%20-

\%20YouTube\%20e\%20a\%20Revolu\%C3\%A7\%C3\%A30\%20Digital\%20Como\%20o \%20maior\%20fen\%C3\%B4meno\%20da\%20cultura\%20participativa\%20transformou \%20a\%20m\%C3\%ADdia\%20e\%20a\%20socieda.pdf. Acesso em: 20 out. 2020.

COSTA, Klébia Ribeiro da; PAZ, Ana Maria de Oliveira. Letramento profissional: estudos em perspectivas. Universidade Federal do Rio Grande do Norte. Revista do GELNE, v.19, n. Especial, 2017. Disponível em: https://periodicos.ufrn.br/gelne/article/view/12592. Acesso em: 05 set. 2020.

COSTA, Sandra Regina Santana; DUQUEVIZ, Barbara Cristina; PEDROZA, Regina Lúcia Sucupira. Tecnologias Digitais como instrumentos mediadores da aprendizagem dos nativos digitais. Revista Quadrimestral da Associação Brasileira de Psicologia Escolar e Educacional, SP. Volume 19, Número 3, Setembro/Dezembro de $2015 . \quad$ Disponível em: 
https://www.scielo.br/pdf/pee/v19n3/2175-3539-pee-19-03-00603.pdf. Acesso em: 13 set. 2020.

DICIO, Dicionário Online de Português. 2021. Disponível em: https://www.dicio.com.br/multi/. Acesso em: 09 jul. 2021.

DRUMOND, Kelly. Alfabetização e letramento: conceitos, relações e práticas. SistemaMaxi. $\quad 30 \quad$ jul. 2020.2 Disponível em: https://www.sistemamaxi.com.br/alfabetizacao-e-letramento/. Acesso em: 15 set. 2020.

GNIPPER, Patrícia. Ranking das redes sociais: as mais usadas no Brasil e no mundo, insights e materiais gratuitos. Resultados Digitais. 21 de janeiro de 2020. Disponível em: https://resultadosdigitais.com.br/blog/redes-sociais-mais-usadas-nobrasil/. Acesso em: 08 set. 2020.

GRANDO, Katlen Böhm. O letramento a partir de uma perspectiva teórica: origem do termo, conceituação e relações com a escolarização. PUCRS - Projeto Observatório da Educação/CAPES. IX ANPED SUL. Seminário de Pesquisa em Educação da $\begin{array}{lllll}\text { Região } & \text { Sul. } & 2012 . & \text { Disponível }\end{array}$ http://www.ucs.br/etc/conferencias/index.php/anpedsul/9anpedsul/paper/viewFile/327 5/235. Acesso em: 11 set. 2020.

GUIMARÃES, Nilma. Português - Afinal, o que é letramento? Planos de Aula. Ensino Médio. UOL. 2020. Disponível em: https://educacao.uol.com.br/planos-deaula/fundamental/portugues-afinal-o-que-e-letramento.htm. Acesso em: 17 out. 2020.

KLEINA, Nilton. A história do YouTube, a maior plataforma de vídeos do mundo [vídeo]. Tecmundo. 11/07/2017 às 11:25. Disponível em: https://www.tecmundo.com.br/youtube/118500-historia-youtube-maior-plataformavideos-do-mundo-video.htm. Acesso em: 15 set. 2020.

RC: 97006

Disponível em: https://www.nucleodoconhecimento.com.br/educacao/compreensaoe-identidades 
KLEINA, Nilton. A história do Orkut, a rede social favorita do Brasil [vídeo]. Tecmundo. 31/07/2018 às 11:00. Disponível em: https://www.tecmundo.com.br/mercado/132464-historia-orkut-rede-social-favorita-dobrasil-video.htm. Acesso em: 15 set. 2020.

KLEINA, Nilton. A história do Facebook, a maior rede social do mundo [vídeo]. Tecmundo. 07/08/2018 às 12:03. Disponível em: https://www.tecmundo.com.br/mercado/132485-historia-facebook-maior-rede-socialdo-mundo-video.htm. Acesso em: 15 set. 2020.

LÉVY, Pierre. Cibercultura. (Trad. Carlos Irineu da Costa). São Paulo: Editora 34, 2009.

MARCUSCHI, L. A. Gêneros Textuais: definição e funcionalidade. In: DIONISIO, A. P.; MACHADO, A. R.; BEZERRA, M. A. (orgs.). Gêneros textuais \& ensino, São Paulo: Parábola Editorial, 2010.

MICHAELIS. Dicionário Brasileiro de Língua Portuguesa. UOL. 2020. Disponível em: https://michaelis.uol.com.br/moderno-portugues/busca/portugues-

brasileiro/aprender/. Acesso em: 01 ago. 2020.

NEW-LONDON-GROUP.jpg. The New London Group. WORKS \& DAYS. 2020. Disponível em: https://newlearningonline.com/transpositionalgrammar/meaning/meaning-overview/new-london-group. Acesso em: 02 set. 2020.

PEREZ, Luana Castro Alves. Analfabetismo funcional. Brasil Escola. 2020 Disponível em: https://brasilescola.uol.com.br/gramatica/analfabetismofuncional.htm. Acesso em 17 jan. 2021.

PEXELS-PHOTO-3768129.jpg. Andrea Piacquadio. Pexels. 2021. Disponível em: https://www.pexels.com/pt-br/foto/foto-de-uma-mulher-falando-com-outra-mulher3768129/. Acesso em: 17 jan. 2021.

RC: 97006

Disponível em: https://www.nucleodoconhecimento.com.br/educacao/compreensaoe-identidades 
PEXELS-PHOTO-5082579.jpg. Cottonbro. Pexels. 2021. Disponível em: https://www.pexels.com/pt-br/foto/aplicativo-app-aplicacao-solicitacao-5082579/. Acesso em: 18 jan. 2021.

ROJO, Roxane. Gêneros e tipos textuais. Glossário CEALE (Centro de Alfabetização, Leitura e Escrita). Faculdade de Educação da UFMG. 2020. Disponível em: http://ceale.fae.ufmg.br/app/webroot/glossarioceale/verbetes/generos-e-tipostextuais. Acesso em: 01 set. 2020.

ROJO, Roxane; BARBOSA, Jacqueline. Hipermodernidade, multiletramentos e gêneros discursos. 1ํed. São Paulo: Parábola Editorial, 2015.

ROJO, Roxane; MOURA, Eduardo. Letramentos Mídias Linguagens. $1^{\circ}$ ed. São Paulo: Parábola Editorial, 2019.

SANTOS V. L. C; SANTOS J. E. As Redes Sociais Digitais e sua Influência na Sociedade e Educação Contemporâneas. HOLOS, Ano 30, Vol. 6 309. 2014. Disponível em: http://www2.ifrn.edu.br/ojs/index.php/HOLOS/article/view/1936/pdf_144. Acesso em: 20 ago. 2020.

SILVA, Luciana Pereira da. Prática textual em língua portuguesa. $2^{\circ}$ ed. Curitiba. PR: IESDE Brasil, 2017.

SOARES, Magda. Letramento e alfabetização: as muitas facetas. Revista Brasileira de Educação. SCIELO. Rev. Bras. Educ. no.25 Rio de Janeiro Jan./Apr. 2004. Disponível em: https://www.scielo.br/scielo.php?pid=S141324782004000100002\&script=sci_arttext\&tlng=pt. Acesso em: 02 set. 2020.

SOUZA, Carlos Henrique Medeiros de; CARDOSO, Carlos. As Redes Sociais Digitais: Um mundo em transformação. Agenda Social. V.5, nำ1, jan-abr/2011, p. 65 
http://www.uenf.br/Uenf/Downloads/Agenda_Social_8427_1312371250.pdf. Acesso em: 31 ago. 2020.

\section{APÊNDICE - REFERÊNCIA NOTA DE RODAPÉ}

2. Para o dicionário Michaelis, o substantivo masculino alfabeto, significa: "sistema de representação dos sons da fala por meio de letras, fonemas, palavras, textos, etc." (MICHAELIS DICIONÁRIO BRASILEIRO DE LÍNGUA PORTUGUESA, 2020).

3. Grafemas podem ser entendidos como: "as unidades escolhidas para grafar sons", neste caso as unidades são as letras. (GLOSSÁRIO CEALE, 2020);

4. Fonema é: "[...] som distintivo em uma língua.", quando se atribui um novo som, tem-se uma nova palavra. (GLOSSÁRIO CEALE, 2020).

5. O contexto do Letramento Profissional visa construir competências, em âmbito corporativo, como conhecimentos de novas técnicas, aprimoramento de qualidades e habilidades (skills) e uso de uma forma ampla e categorizada de linguagens através dos mais diversos formatos e meios para aumento da produtividade do profissional (COSTA; PAZ, 2017).

6. Entende-se por conteúdos midiáticos, conteúdos que mesclam imagens, sons e textos de forma conjugada ou não.

7. Faziam parte do grupo em ordem alfabética: Allan Luke; Bill Cope; Carmen Luke; Courtney Cazden; Gunther Kress; James Paul Gee; Marin Nakata; Mary Kalantzis; Norman Fairclough; Sarah Michaels.

8. O prefixo multi vem no sentido de indicar múltiplas coisas, múltiplas vezes e sua origem é na palavra em latim multu (DICIO, 2021).

9. O sentido básico do hyperlink é fazer a ligação (conexão) entre diferentes partes de um texto, sendo assim basicamente uma área "clicável" em um texto será conectada imediatamente a outra e assim sucessivamente.

RC: 97006

Disponível em: https://www.nucleodoconhecimento.com.br/educacao/compreensaoe-identidades 
10. O sentido do letramento digital neste contexto é a necessidade praticamente obrigatória de entendimentos dos seus usuários em navegar e manipular suas interfaces digitais;

11. O termo semiótica está atrelado ao processo do significado de termos e dos seus signos atrelados.

12. O termo utilizado serve para expressar as constantes remoções de contas de usuários que o Facebook relata realizar, seja por motivos políticos, religiosos ou mesmo políticas contra a privacidade de empresas e usuários.

13. O Instagram Stories é um recurso que permite o compartilhamento, basicamente em tempo real, de vídeos e imagens, que podem desaparecer após o período de 24 horas, com a interação de figuras (emojis) e desenhos.

14. No sentindo do acesso livre a todos, sempre mediante regras simples, como um cadastro prévio, escolha de gostos, desejos e qualificações do usuário que pretendo ingressar na rede social;

15. Neste quesito expomos o país como celeiro inato da origem e popularização da web, além da nação das principais empresas de tecnologia mundial.

Enviado: Julho, 2021.

Aprovado: Setembro, 2021. 